\title{
Breeding structure of a colonizing species: Aedes albopictus (Skuse) in peninsular Malaysia and Borneo
}

\author{
William C. Black IV, \\ William A. Hawley, \\ Karamjit S. Rai and \\ George B. Craig Jr.
}

\author{
Department of Biological Sciences, \\ University of Notre Dame, Notre Dame, IN 46556.
}

\begin{abstract}
The mosquito, Aedes albopictus, has recently become established in a number of cities throughout the United States. An initial survey of allozyme and genotypic frequencies in U.S. populations (Black et al., 1988) revealed an extensive amount of local differentiation of populations and suggested that much genetic drift may have accompanied colonization. A study of gene flow was initiated in native habitats of Ae. albopictus in Malaysia to determine if the result observed in the U.S. was a consequence of colonization or simply followed the natural breeding structure of the species. Allelic and genotypic frequencies were monitored at ten enzymatic loci in 11 populations from peninsular Malaysia and Borneo. Multiple populations were sampled within the districts of Kuala Lumpur and Kuala Trengganu. Peninsular Malaysian and Borneo populations were strongly genetically differentiated. Allele frequencies were significantly different among and within districts in both regions. Variance in allele frequencies among all collections was partitioned into the variance among regions, districts within regions and collections within districts. Almost all of the variance within regions was attributable to local differentiation suggesting that genetic drift is an important component of the natural breeding structure of this species. This indicates that the large amounts of local differentiation found in U.S. populations was not a consequence of recent colonization.
\end{abstract}

\section{INTRODUCTION}

The native habitat of the medically significant mosquito, Aedes albopictus (Skuse), extends north from Madagascar throughout the Indomalayan and Oriental regions, China and Japan (Ho et al. 1973; Huang, 1972; Knight and Stone, 1977). It became established in Hawaii between 1830 and 1896 (Hardy, 1960; Joyce, 1961) and within the past twenty years has colonized the Solomon and Santa Cruz Islands in the South Pacific (Belkin, 1962; Elliott, 1980; Pashley and Pashley, 1983). During the summer of 1985 the species was discovered throughout Harris County, Texas (Sprenger and Wuithiranyagool, 1986). Since that time the species has become widely distributed in the United States, as far west as San Antonio, Texas, east to Jacksonville, Florida and north as far as Chicago, Illinois and Baltimore, Maryland. Comparison of allozyme frequencies (Black and Rai, unpublished) and diapause data (Hawley et al., 1987) from U.S. populations with populations collected throughout the world range of $A e$. albopictus suggest that the U.S. populations origi- nated in Japan. Hawley et al., (1987) present data indicating that the mosquito was introduced in commercial tyre shipments.

The population genetics of colonization is an integral component of many models of speciation (Dobzhansky, 1970; Lewontin, 1974; Mayr, 1963; Wright, 1978) and as such the recent introduction of Ae. albopictus may provide valuable insights into the types of genetic events which initially accompany colonization. Black et al. (1988) examined allozyme frequencies in adults and eggs from a number of U.S. cities during the summer and fall of 1986. In this initial survey we found large amounts of genetic differentiation among collections within the cities of New Orleans, Louisiana and Houston, Texas. The amount of variation within these cities was four times the amount found among cities. This suggested that drift may have initially played an important role in differentiating populations. However, no studies of local gene flow have been made of Ae. albopictus populations in its native habitat. It was therefore unknown whether the genetic drift observed in U.S. populations was a consequence of recent 
colonization or characteristic of the natural breeding structure of the species.

Recently, the opportunity became available to collect Ae. albopictus in Malaysia. The species is thought to have originated in southeast Asia (Smith, 1956). While Malaysia is probably not the source of the U.S. population it nevertheless provided the opportunity to study the breeding structure of the species in native habitats. In this paper we describe gene flow among Ae. albopictus populations in native habitats in Malaysia. Collections were made from two districts in peninsular Malaysia and two districts on the island of Borneo. Numerous collections were made within the districts of Kuala Lumpur and Kuala Trengganu in peninsular Malaysia. By analyzing the amount of genetic differentiation within and among districts, we describe patterns of local gene flow. It was hoped that comparison of these results with those obtained in the U.S. would identify the types of genetic changes which accompany colonization.

\section{METHODS}

Aedes albopictus eggs were collected using ovitraps during November, 1987. Ovitraps consisted of $400 \mathrm{ml}$ red plastic cups half-filled with tap water containing a $5 \times 12 \mathrm{~cm}$ waterlogged balsawood oviposition paddle. In Kuala Lumpur and Kuala Trengganu district, West Malaysia (fig. 1), ovitraps were placed at ground level at sites positive for Ae. albopictus. Numerous Ae. albopictus males and females were attracted to workers within a few minutes, indicating the presence of a large $A e$. albopictus population. In Sabah and Sarawak, traps were placed at locations where it was thought likely that Ae. albopictus would be present, but adult activity was observed only at Serian, Sarawak. No Ae. aegypti was observed at any site. Four or five ovitraps were placed from 5-100 m apart at every site. Ovitraps were left in place 3-4 days before paddles were collected. Paddles were transported to the University of Notre Dame

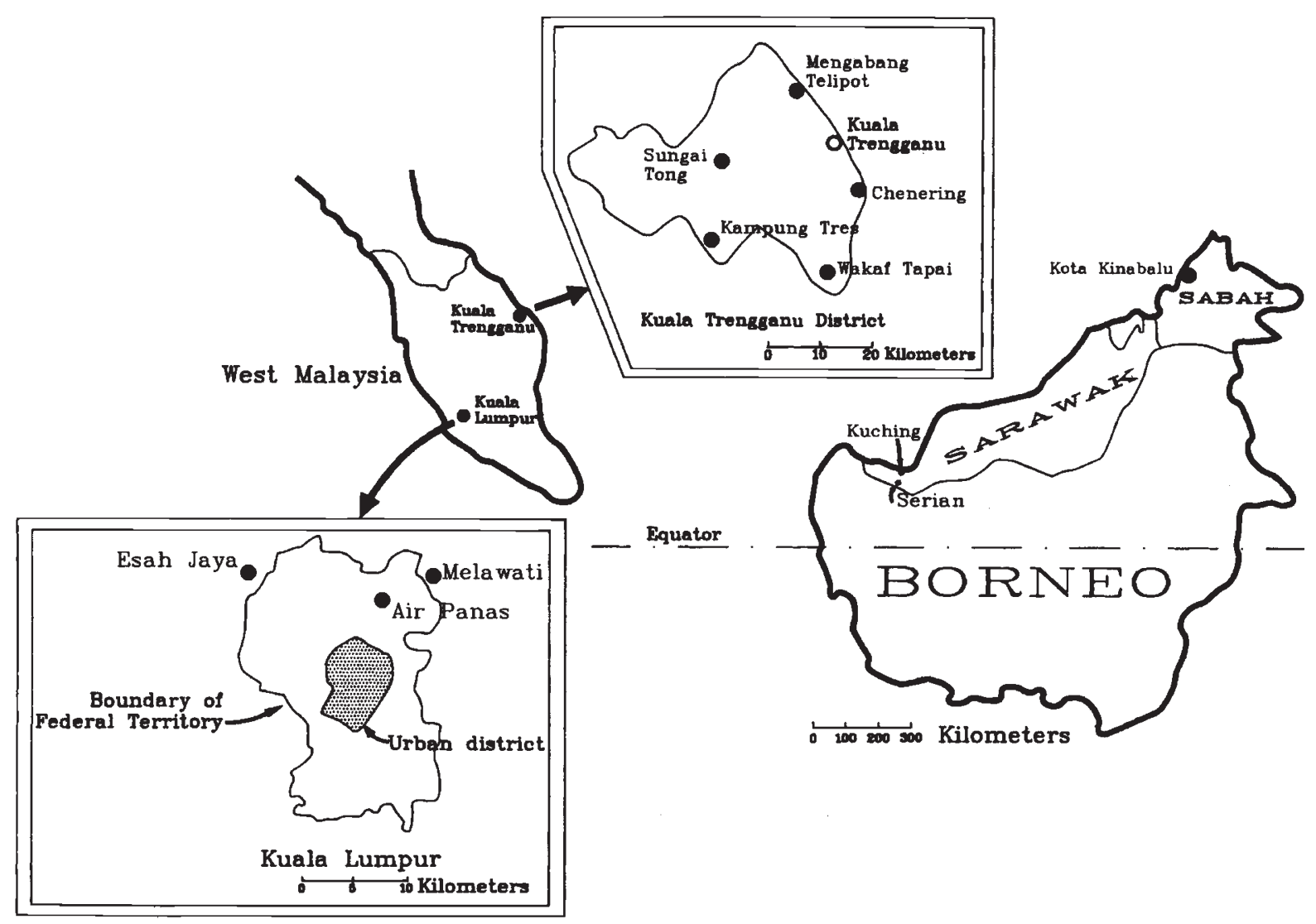

Figure 1 Sites in Kuala Lumpur and Kuala Trengganu in Peninsular Malaysia and Sarawak and Sabah in Borneo at which Ae. albopictus was collected for the present study. 
for hatching and rearing in mid-December, 1987. Adult mosquitoes from all ovitraps at a collection site were pooled and transferred to $\mathrm{a}-70^{\circ} \mathrm{C}$ freezer to await electrophoresis.

Ovitraps in Kuching and Kota Kinabalu were placed in wooded areas adjacent to large hospitals in these cities. In the large village of Serian (population approx. 10,000), traps were placed in undergrowth near human dwellings. Though collections from Kuala Lumpur (population one million) were made within or near its boundary, traps were placed in areas with a large amount of thick vegetation and low human population density. Traps in Air Panas were located in a wooded tract adjacent to an abandoned mining pool. Several dozen wooden houses were located $0.5 \mathrm{~km}$ from this site. Traps in Melawati were placed in a roadside strip of thick secondary forest located several hundred meters from a modern shopping complex. Both wooden (kampung style) houses and suburban tract housing were located within $1 \mathrm{~km}$ of this site. Ovitraps in Esah Jaya were placed in and near a small illegal dump site adjacent to a small muslim graveyard. This site was located about $100 \mathrm{~m}$ from a large expanse of suburban tract housing. Collection sites in Kuala Trengannu district in northeast peninsular Malaysia were rural. Chenering is a coastal roadside site with thick vegetation and a large number of discarded coconut husks (resulting in a large number of biting Ae. albopictus and Armigeres mosquitoes). Scattered wooden houses were located within several hundred meters of this site. Wakaf Taipei is an extensive, operational rubber plantation. Traps were placed in a narrow wooded strip on the plantation's border. Both the Kampung Tres and Sungai Tong sites were abandoned small scale rubber holdings with very few, scattered human dwellings within several kilometers. Ovitraps in Mengabang Telipot (population 4000) were placed in an approximately 1 hectare wooded area on the outskirts of the village.

Allozymes were resolved at 10 loci using vertical polyacrylamide gel electrophoresis on Hoefer SE600 gel boxes. Methods were derived from those of Munstermann (1979). A litre of $40 \times$ Tris-Citrate buffer was made by dissolving $94.06 \mathrm{~g}(0.78 \mathrm{M})$ of Tris into $700 \mathrm{ml}$ of distilled water, titrating to $p \mathrm{H} 7 \cdot 1$ with $1 \mathrm{M}$ citric acid and bringing it to volume with distilled water. This buffer was diluted 1:39 with distilled water to make the electrode buffer and 1:19 for the gel buffer. A litre of $10 \times$ Tris-Borate-EDTA buffer was made by dissolving $98.31 \mathrm{~g}(0.81 \mathrm{M})$ Tris, $12.50 \mathrm{~g}(0.20 \mathrm{M})$ Boric acid, and $5.58 \mathrm{~g}(15 \mathrm{mM})$ EDTA (disodium) in enough distilled water to bring the volume to 1 litre. This buffer was diluted 1:9 with distilled water to make the electrode and gel buffers. Polyacrylamide gels (4.75 per cent Monomer, 0.25 per cent Bisacrylamide) were poured with the appropriate buffer, 0.5 per cent Photoflow, $0 \cdot 15$ per cent TEMED and 0.05 per cent Ammonium persulfate. Mosquitoes were ground in $25 \mu \mathrm{l}$ of grinding buffer (10 per cent Sucrose, 0.01 per cent bromophenol blue, 1 per cent Triton X-100 dissolved in Tris-citrate electrode buffer diluted $1: 5) .2 \cdot 5 \mu$ l of sample were loaded per gel. Both systems were run at a constant 350 volts for 3 hours. ACON (aconitase), HAD (hydroxyl acid dehydrogenase), MDH (malic acid dehydrogenase), IDH (isocitrate dehydrogenase) and $\alpha$-GPDH $(\alpha$-glycerophosphate dehydrogenase) were resolved with the Tris-citrate system. PGI (phosphoglucoisomerase), 6-PGDH (6phosphogluconic acid dehydrogenase), PGM (phosphoglucomutase), EST (esterase) and GOT (glutamate oxaloacetate transaminase) were resolved using the Tris-borate-EDTA system. Alleles were scored with reference to the most common allele $(\mathrm{rf}=1.00)$ from the Memphis, Tennessee (U.S.A.) population.

Genestats (Black and Krafsur, 1985b) and BIOSYS (Swofford and Selander, 1982) were used to analyze the data. Weir and Cockerham's (1984) $\chi^{2}$ test for random mating was employed. Wright's (1978) analysis of allele frequencies in subdivided populations was used to partition variance among all samples into nested effects among regions, districts in regions and collections within districts. For this and the contingency $\chi^{2}$ analysis, collections from Kampung Tres, Sungai Tong and Kuching were dropped because of small sample sizes.

\section{RESULTS}

Allozyme frequencies in populations of $A e$. albopictus from peninsular Malaysia are listed in table 1. The frequencies of allozymes in Borneo populations are listed in table 2 . Average expected heterozygosities were similar in all collections. Nei's unbiased genetic distances (1978) were calculated among all collections, among districts and between regions (table 3). Peninsular Malaysian populations were strongly genetically differentiated from the Borneo populations. Most of this differentiation was due to the inverse frequencies of $\alpha-G p d h$ alleles in the two populations. Removal of this locus from the genetic distance analysis indicated that populations from the two regions were otherwise similar. 
Table 1 Allele frequencies and sample sizes $(N)$ at three collections sites in Kuala Lumpur and five sites in Kuala Trengganu in peninsular Malaysia

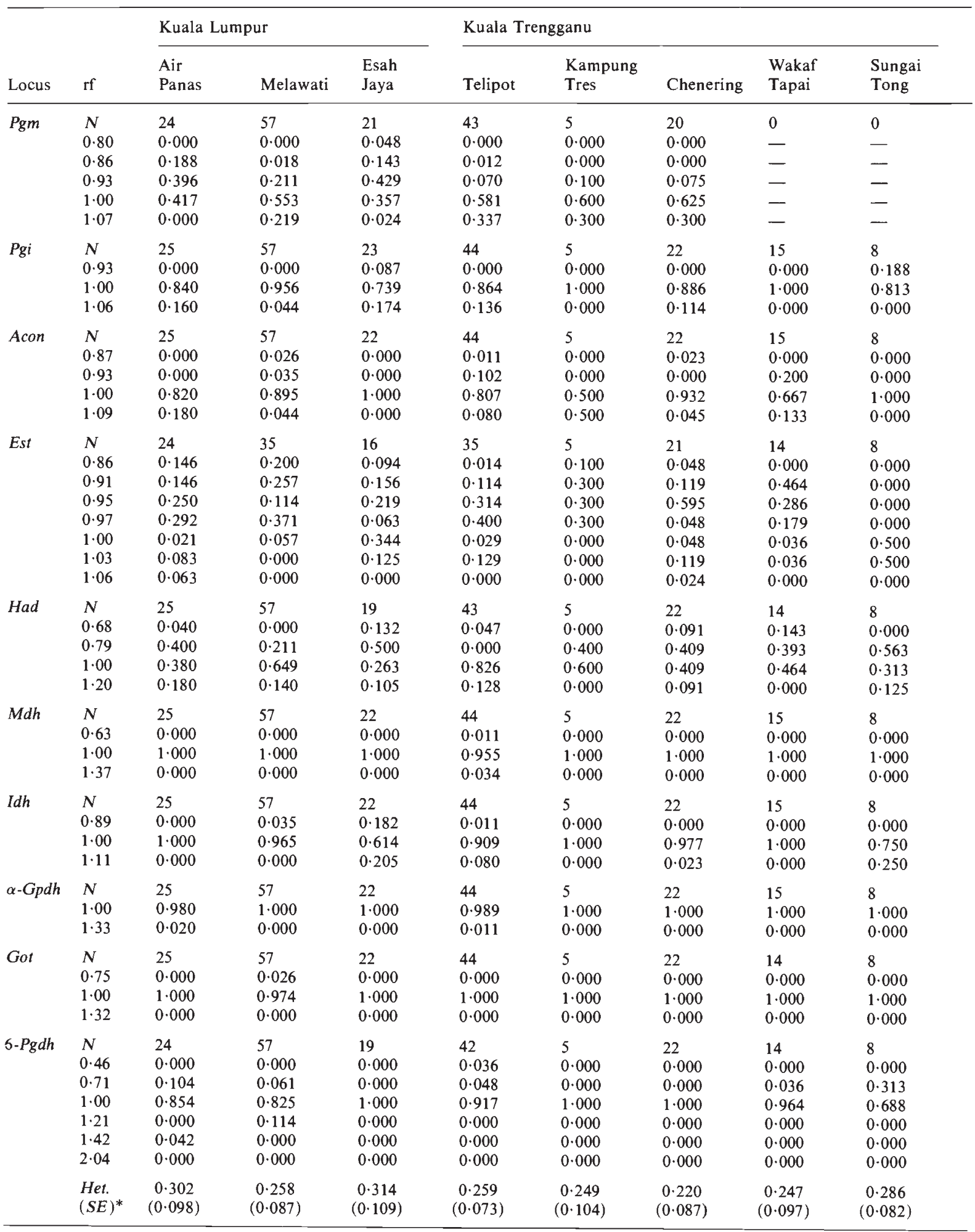

\footnotetext{
* The average expected genic heterozygosity and standard error among the 10 loci.
} 
Table 2 Allele frequencies and sample sizes $(N)$ at three collection sites in Borneo

\begin{tabular}{|c|c|c|c|c|}
\hline Locus & If & $\begin{array}{l}\text { Kota } \\
\text { Kinabalu }\end{array}$ & Kuching & Serian \\
\hline Pgm & $\begin{array}{l}N \\
0.80 \\
0.86 \\
0.93 \\
1.00 \\
1.07\end{array}$ & $\begin{array}{l}17 \\
0.000 \\
0.118 \\
0.353 \\
0.500 \\
0.029\end{array}$ & $\begin{array}{l}7 \\
0.000 \\
0.000 \\
0.000 \\
0.286 \\
0.714\end{array}$ & $\begin{array}{l}32 \\
0.000 \\
0.000 \\
0.266 \\
0.672 \\
0.063\end{array}$ \\
\hline$P g i$ & $\begin{array}{l}N \\
0.93 \\
1.00 \\
1.06\end{array}$ & $\begin{array}{l}17 \\
0.235 \\
0.765 \\
0.000\end{array}$ & $\begin{array}{l}7 \\
0.071 \\
0.929 \\
0.000\end{array}$ & $\begin{array}{l}35 \\
0 \cdot 200 \\
0 \cdot 643 \\
0.157\end{array}$ \\
\hline Acon & $\begin{array}{l}N \\
0.87 \\
0.93 \\
1.00 \\
1.09\end{array}$ & $\begin{array}{l}16 \\
0.000 \\
0.000 \\
0.750 \\
0.250\end{array}$ & $\begin{array}{l}7 \\
0 \cdot 000 \\
0 \cdot 143 \\
0 \cdot 714 \\
0.143\end{array}$ & $\begin{array}{l}34 \\
0.000 \\
0.000 \\
0.853 \\
0.147\end{array}$ \\
\hline Est & $\begin{array}{l}N \\
0.86 \\
0.91 \\
0.95 \\
0.97 \\
1.00 \\
1.03 \\
1.06\end{array}$ & $\begin{array}{l}16 \\
0.000 \\
0.000 \\
0.000 \\
0.563 \\
0.219 \\
0.125 \\
0.094\end{array}$ & $\begin{array}{l}6 \\
0.000 \\
0.167 \\
0.000 \\
0.083 \\
0.250 \\
0.000 \\
0.500\end{array}$ & $\begin{array}{l}32 \\
0 \cdot 000 \\
0.203 \\
0.297 \\
0.188 \\
0.063 \\
0.250 \\
0.000\end{array}$ \\
\hline Had & $\begin{array}{l}N \\
0.68 \\
0.79 \\
1.00 \\
1.20\end{array}$ & $\begin{array}{l}17 \\
0.000 \\
0.000 \\
1.000 \\
0.000\end{array}$ & $\begin{array}{l}7 \\
0 \cdot 000 \\
0 \cdot 000 \\
1 \cdot 000 \\
0.000\end{array}$ & $\begin{array}{l}35 \\
0.029 \\
0.014 \\
0.929 \\
0.029\end{array}$ \\
\hline$M d h$ & $\begin{array}{l}N \\
0.63 \\
1 \cdot 00 \\
1 \cdot 37\end{array}$ & $\begin{array}{l}17 \\
0 \cdot 000 \\
1 \cdot 000 \\
0.000\end{array}$ & $\begin{array}{l}7 \\
0 \cdot 000 \\
1 \cdot 000 \\
0 \cdot 000\end{array}$ & $\begin{array}{l}34 \\
0.059 \\
0.941 \\
0.000\end{array}$ \\
\hline$I d h$ & $\begin{array}{l}N \\
0.89 \\
1.00 \\
1 \cdot 11\end{array}$ & $\begin{array}{l}17 \\
0 \cdot 206 \\
0.794 \\
0.000\end{array}$ & $\begin{array}{l}7 \\
0 \cdot 286 \\
0.714 \\
0.000\end{array}$ & $\begin{array}{l}35 \\
0.014 \\
0.986 \\
0.000\end{array}$ \\
\hline$\alpha-G p d h$ & $\begin{array}{l}N \\
1 \cdot 00 \\
1 \cdot 33\end{array}$ & $\begin{array}{l}17 \\
0.059 \\
0.941\end{array}$ & $\begin{array}{l}7 \\
0.429 \\
0.571\end{array}$ & $\begin{array}{l}35 \\
0 \cdot 114 \\
0.886\end{array}$ \\
\hline Got & $\begin{array}{l}N \\
0.75 \\
1.00 \\
1.32\end{array}$ & $\begin{array}{l}17 \\
0.000 \\
0.794 \\
0.206\end{array}$ & $\begin{array}{l}7 \\
0 \cdot 000 \\
1 \cdot 000 \\
0 \cdot 000\end{array}$ & $\begin{array}{l}35 \\
0.000 \\
1.000 \\
0.000\end{array}$ \\
\hline 6-Pgdh & $\begin{array}{l}N \\
0 \cdot 46 \\
0 \cdot 71 \\
1.00 \\
1.21 \\
1.42 \\
2 \cdot 04\end{array}$ & $\begin{array}{l}17 \\
0.000 \\
0.000 \\
1.000 \\
0.000 \\
0.000 \\
0.000\end{array}$ & $\begin{array}{l}7 \\
0.000 \\
0.214 \\
0 \cdot 786 \\
0 \cdot 000 \\
0 \cdot 000 \\
0 \cdot 000\end{array}$ & $\begin{array}{l}35 \\
0.000 \\
0.029 \\
0.914 \\
0.043 \\
0.000 \\
0.014\end{array}$ \\
\hline & $\begin{array}{l}\text { Het. } \\
(S E)^{*}\end{array}$ & $\begin{array}{c}0.281 \\
(0.077)\end{array}$ & $\begin{array}{c}0.311 \\
(0.081)\end{array}$ & $\begin{array}{c}0.269 \\
(0.269)\end{array}$ \\
\hline
\end{tabular}

* The average expected genic heterozygosity and standard error among the 10 loci.
Pairwise contingency $\chi^{2}$ tests indicated that allele frequencies were significantly different among all districts (analyses not shown). Table 4 lists the results of contingency $\chi^{2}$ analysis to test for homogeneity of allele frequencies among collections within Kuala Lumpur and Kuala Trengganu. Populations within both districts were significantly differentiated.

The variance in allele frequencies among all collections was partitioned using a nested random effects model following Wright (1978). Collections were nested within districts and districts were nested within regions. Table 5 shows that, with all loci included, 52 per cent of the total variance among all collections was attributable to differences among regions. But with the $\alpha-G$ pdh locus removed, the variance among regions dropped to 2 per cent of the total. In a third analysis, esterase was removed because in a locus by locus analysis (data not shown) it was determined that variation at this locus contributed most to the local variance. Removal of this locus had no effect on the amount of variance attributable to local differentiation. In all analyses, the amount of variance among collections within a district was consistently 4-5 times as large as the amount of variance among districts.

Observed genotypic frequencies were compared with those expected under random mating (Hardy-Weinberg expectations). We found 8 of 71 tests to show significant deviations from expectations. This was not significantly greater than expected with a type I error rate of 5 per cent $(0.05 \times 71=$ $3 \cdot 55$ significant observations, $\chi^{2}[1 \mathrm{df}]=3 \cdot 36, P \geqq$ $0 \cdot 05$ ). Significant results were homogeneously distributed among collections. Four of the significant results were observed at the Est locus, 3 at the Had locus and 1 at the Pgm locus. No consistent trend towards heterozygote excess or deficiency was noted among significant results. In general, mosquitoes appeared to mate at random within populations.

\section{DISCUSSION}

The large genetic distance observed between peninsular Malaysia and Borneo populations was chiefly attributable to differentiation at the $\alpha$-Gpdh locus. A survey of allozyme frequencies among populations throughout the world range of $A e$. albopictus (Black and Rai, unpublished) indicates that this variant is unique to Borneo. This suggests either that very little migration exists between populations in the two regions or that selection acts to maintain alleles in almost inverse frequen- 
Table 3 Nei's unbiased genetic distances among collections, districts and regions in Malaysia

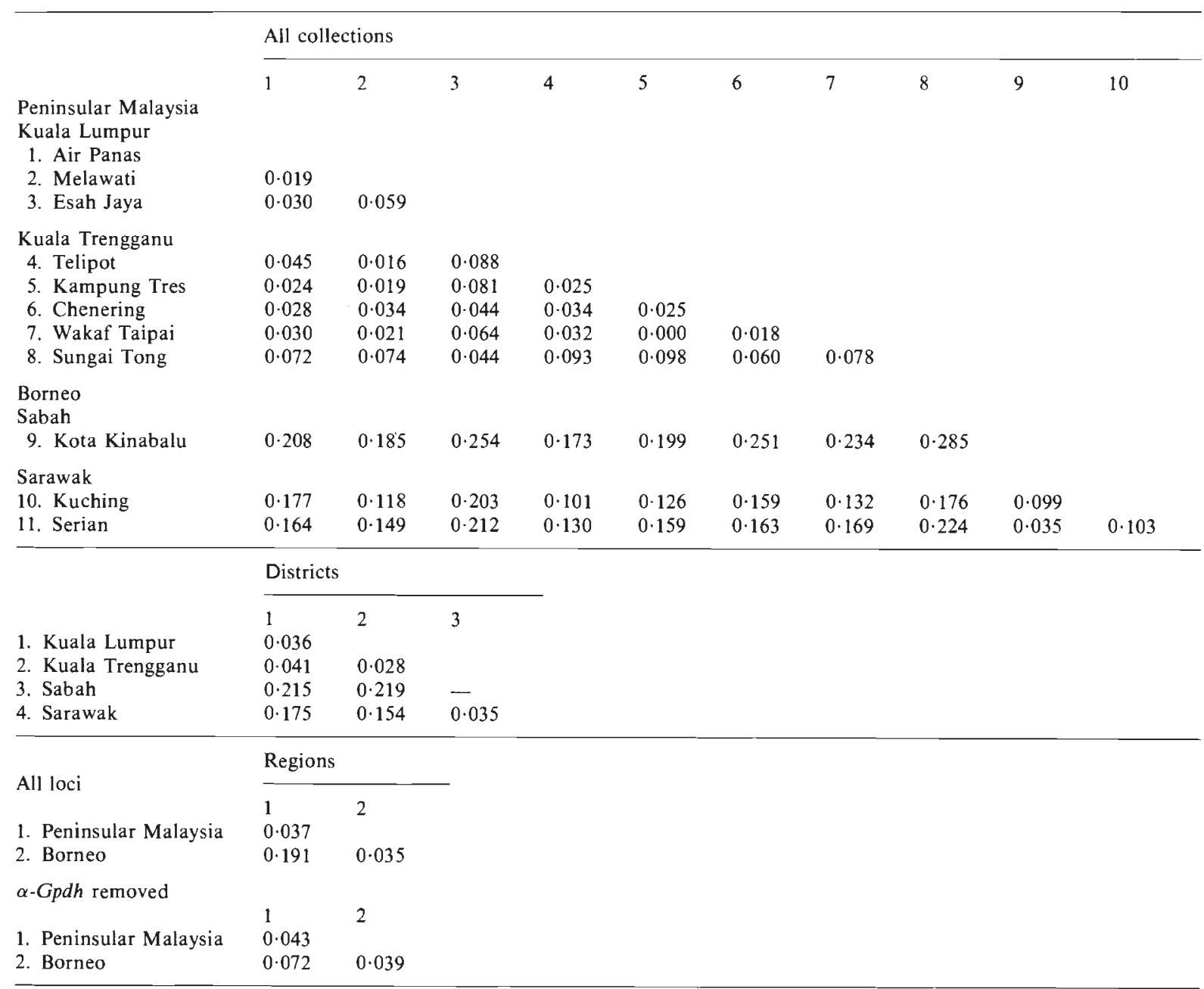

Table 4 Contingency $\chi^{2}$ test for homogeneity of allele frequencies among collections in Kuala Lumpur and Kuala Treng. ganu in peninsular Malaysia

\begin{tabular}{lcccc}
\hline & \multicolumn{2}{c}{ Kuala Lumpur } & \multicolumn{2}{c}{ Kuala Trengganu } \\
\cline { 2 - 4 } \cline { 5 - 5 } Locus & $\mathrm{df}$ & $\chi^{2}$ & $\mathrm{df}$ & \multicolumn{2}{c}{$\chi^{2}$} \\
\hline Pgm & 8 & $48 \cdot 69^{* * *}$ & 6 & $1 \cdot 78$ \\
Pgi & 4 & $24 \cdot 04^{* * *}$ & 2 & $4 \cdot 48$ \\
Acon & 6 & $19 \cdot 95^{* *}$ & 6 & $11 \cdot 93$ \\
Est & 12 & $50 \cdot 35^{* * *}$ & 12 & $41 \cdot 08^{* * *}$ \\
Had & 6 & $34 \cdot 99^{* * *}$ & 6 & $50 \cdot 63^{* * *}$ \\
Idh & 4 & $54 \cdot 29^{* * *}$ & 4 & $4 \cdot 84$ \\
Gpdh & 2 & $3 \cdot 18$ & 2 & $0 \cdot 85$ \\
Got & 2 & $2 \cdot 51$ & - & - \\
Mdh & - & - & 4 & $3 \cdot 45$ \\
Pgdh & 6 & $21 \cdot 01^{* * *}$ & 4 & - \\
\hline Total & 50 & $259 \cdot 01^{* * *}$ & 46 & $123 \cdot 88^{* * * *}$ \\
\hline
\end{tabular}

** $P \leqq 0 \cdot 01$.

*** $P \leqq 0.001$ cies. Given the large genetic distances among these two relatively close regions, it is likely that a great deal more differentiation exists among islands throughout Indonesia and east through the Solomon Islands. This highlights the need for more extensive examination of breeding structure throughout these regions.

The amount of variation in allele frequencies among collection sites within districts was 4-5 times as large as the variation among districts. The same phenomenon was observed among local populations of Ae. albopictus in the United States (Black et al., 1988). We attributed this variation in local U.S. populations to genetic drift associated with restricted gene flow among newly established populations.

In the current study there are three possible explanations for the observed local differentiation. It is possible that we collected offspring represent- 
Table 5 Nested analysis of variance of allele frequencies among collection sites in peninsular Malaysia and Borneo.

Collections are nested within districts and districts are nested within regions

\begin{tabular}{|c|c|c|c|c|c|c|}
\hline \multirow[b]{2}{*}{ Source } & \multicolumn{2}{|l|}{ All loci } & \multicolumn{2}{|c|}{$\alpha-G p d h$ removed } & \multicolumn{2}{|c|}{ Est removed } \\
\hline & Variance & $\%$ Total & Variance & $\%$ Total & Variance & $\%$ Total \\
\hline Regions & $0 \cdot 316$ & $52 \cdot 2 \%$ & $0 \cdot 007$ & $2 \cdot 4 \%$ & $0 \cdot 335$ & $63 \cdot 4 \%$ \\
\hline District (Regions) & 0.055 & $9 \cdot 1 \%$ & 0.054 & $18 \cdot 3 \%$ & 0.032 & $6 \cdot 1 \%$ \\
\hline Collections (District (Regions)) & $0 \cdot 234$ & $38 \cdot 7 \%$ & $0 \cdot 234$ & $79 \cdot 3 \%$ & $0 \cdot 161$ & $30 \cdot 5 \%$ \\
\hline All. collections & 0.605 & & $0 \cdot 295$ & & 0.528 & \\
\hline
\end{tabular}

ing few families such that the observed differentiation is a consequence of sampling. We consider this unlikely because multiple ovitraps were collected at each collection site, high densities of $A e$. albopictus existed at each site, and Ae. albopictus does not oviposit whole egg batches in a single container (Rozeboom et al., 1971). However, in principle, little migration is required to make local populations panmictic within a district and, as such, either selection or genetic drift must be acting to create this local differentiation.

Under a model of selection, populations in districts might be panmictic but local selection pressures act to differentiate subpopulations. We consider this model unlikely because there was less variance among districts than among collections within districts. For selection to create this result there would have to be a similar range of microhabitats in both districts and these habitats would have to be sampled equally. A more parsimonious explanation is that much genetic drift accompanies the establishment of local populations. Under this model, local subpopulations are founded by few parents and the effective migration rate is sufficiently restricted to maintain local differentiation. Studies on dispersal of laboratory reared Ae. albopictus in the field in both Hawaii (Bonnet and Worcester, 1946) and Japan (Mori, 1979) indicate that individuals may migrate a maximum of 200 metres in their lifetime. However, no studies have been done on wild Ae. albopictus, nor have any such investigations been performed in southeast Asia. It is therefore difficult to judge the likelihood that the observed local differentiation is maintained by limited migration.

These results indicate, contrary to original predictions (Black et al., 1988), that the amount of differentiation observed among local populations of Ae. albopictus in the United States is not a consequence of recent colonization but rather an attribute of the natural breeding structure of the species. However, the similarity of breeding structures in Malaysia and the U.S. is unexpected given the marked differences in the distribution and quality of breeding resources in the two regions. Tyres and other discarded containers constitute the majority of oviposition sites for Ae. albopictus in the U.S. The distribution of these varies a great deal from city to city, but in general these constitute sparse oviposition resources. It is easy to envisage genetic drift developing under these circumstances. A few gravid females may locate and oviposit in a group of discarded tyres. The offspring, failing to locate other oviposition sites, oviposit in the same tires. In contrast, Malaysian Ae. albopictus breed in a large variety of commonly found containers. Any artificial container, coconut husk, bamboo stump, or treehole is quite likely to contain Ae. albopictus (Ho et al., 1973). Thus, the distribution of oviposition sites in Malaysia is considerably more continuous than that in the U.S., making this scenario much less plausible. Our results emphasize the need for a more extensive study of breeding structure coupled with ecological and behavioral investigations to identify local barriers to gene flow in this and other native habitats of Ae. albopictus.

Acknowledgements We thank Mr Alan Quah Lean Cheng, En Abdul Ghawi bin Ali, Mr Chang Moh Seng, Mr Nagum Jute, Mr John Lah Jau and Dr Jeffrey Hii for assistance in collecting Ae. albopictus. Dr Leonard Munstermann provided valuable advice in setting up the electrophoresis systems. This work was supported by NIH grant 5R01 AI-21443 to K.S.R. and AI022753 to G.B.C.

\section{REFERENCES}

BELKIN, J. N. 1962. Mosquitoes of the South Pacific (Diptera. Culicidae), 2 Vols. University of California Press, Berkeley. BLACK, W. C. IV AND KRAFSUR, E. S. 1985. A FORTRAN program for analysis of genotypic frequencies and description of the breeding structure of populations. Theor. Appl. Genet., 70, 484-490.

BLACK, W. C. IV, FERRARI, J. A., RAI, K. S. AND SPRENGER, D. 1988. Breeding structure of a colonizing species: Aedes albopictus (Skuse) in the United States. Heredity, 60, 173181. 
BONNET, D. D. AND WORCESTER, D. J. 1946. The dispersal of Aedes albopictus in the territory of Hawaii. Am. J. Trop. Med. Hyg., 26, 465-476.

DOBZhansKY, TH. 1970. Genetics of the Evolutionary Process. Columbia University Press, New York.

ELliOTT, S. A. 1980. Aedes albopictus in the Solomon and Santa Cruz Islands, South Pacific. Trans. R. Soc. Trop. Med. Hyg., 74, 747-748.

HARDY, D. E. 1960. Culicidae. In Zimmerman, E. C. (ed.) Insects of Hawaii, vol. 10, University of Hawaii Press, pp. 18-22, 81-90.

HAWLEY, W. A., REITER, P., COPELAND, R. S., PUMPUNI, C. B. AND CRAIG, G. B. 1987. Aedes albopictus in North America: Probable introduction in used tires from Northern Asia. Science, 236, 1114-1116.

HO, E. C., CHAN, D. L. AND CHAN, Y. C. 1973. The biology and bionomics of Aedes albopictus (Skuse). In Chan, Y. C., Chan, K. L. and Ho, B. C. (eds) Vector Control in Southeast Asia, pp. 125-143.

HUANG, Y. M. 1972. Contributions to the mosquito fauna of Southeast Asia. XIV. The subgenus Stegomyia of Aedes in Southeast Asia. I. The scutellaris groups of species. Contrib. Am. Ent. Inst. (Ann Arbor)., 9, 1-109.

JOYCE, C. R. 1961. Potentialities for accidental establishment of exotic mosquitoes in Hawaii. Proc. Hawaiian. Entomol. Soc., 17, 403-413.

KNIGHT, K. L. AND STONE, A. 1977. A catalog of the mosquitoes of the world. (Diptera: Culicidae), 2nd ed. Thomas Say Foundation, vol. 6. Entomol. Soc. Am., 610pp.

LEWONTIN, R. C. 1974. The Genetic Basis of Evolutionary Change. Columbia University Press, New York.

MAYR, E. 1963. Animal Species and Evolution. Belknap Press of Harvard University Press, Cambridge, Mass.
MORI, A. 1979. Effects of larval density and nutrition on some attributes of immature and adult Aedes albopictus in the field. Trop. Medicine (Nagasaki), 21, 85-103.

MUNSTERMANN, L. E. 1979. Isozymes of Aedes aegypti: Phenotypes, Linkage and Use in the Genetic Analysis of Sympatric Subspecies populations in East Africa, $\mathrm{Ph}$.D. Dissertation. University of Notre Dame. 176pp.

NEI, M. 1978. Estimation of average heterozygosity and genetic distance from a small number of individuals. Genetics, 89 , $583-590$

PASHLEY, D. N. AND PASHLEY, D. P. 1983. Observations on Aedes (Stegomyia) mosquitoes in Micronesia and Melanesia. Mosq. Syst., 15, 41-49.

ROZEBOOM, L. E., ROSEN, L. AND IKEDA, J. 1973. Observations on oviposition by Aedes (S.) albopictus Skuse and $\boldsymbol{A}$. (S.) polynesiensis Marks in nature. J. Med. Ent., 10,397-399.

SMITH, C. E. G. 1956. The history of dengue in tropical asia and its relationship to the mosquito Aedes aegypti. J. Trop. Med. Hyg., 59, 243-252.

SPRENGER, D. AND WUITHIRANYAGOOL, T. 1986. The discovery and distribution of Aedes albopictus in Harris County, Texas. J. Am. Mosq. Cont. Assoc., 2, 217-219.

SWOFFORD, D. L. AND SELANDER, R. B. 1981. BIOSYS-1: a FORTRAN program for the comprehensive analysis of electrophoretic data in population genetics and systematics. J. Hered., 72, 281-283.

WEIR, B. S. AND COCKERHAM, C. C. 1984. Estimating Fstatistics for the analysis of population structure. Evolution $38,1358-1370$.

WRIGHT, S. 1978. Evolution and the genetics of populations, Vol. $I V$, Variability within and among natural populations. University of Chicago Press, Chicago. 